\title{
Disparities in the Use of Neoadjuvant Therapy for Resectable Pancreatic Ductal Adenocarcinoma
}

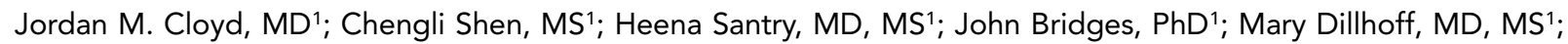
Aslam Ejaz, MD, MPH ${ }^{1}$; Timothy M. Pawlik, MD, MPH, PhD'; and Allan Tsung, MD ${ }^{1}$

\begin{abstract}
Background: Current guidelines support either immediate surgical resection or neoadjuvant therapy (NT) for patients with resectable pancreatic ductal adenocarcinoma (PDAC). However, which patients are selected for NT and whether disparities exist in the use of NT for PDAC are not well understood. Methods: Using the National Cancer Database from 2004 through 2016, the clinical, demographic, socioeconomic, and hospital-related characteristics of patients with stage I/II PDAC who underwent immediate surgery versus NT followed by surgery were compared. Results: Among 58,124 patients who underwent pancreatectomy, 8,124 (14.0\%) received NT whereas 50,000 (86.0\%) did not. Use of NT increased significantly throughout the study period (from $3.5 \%$ in 2004 to $26.4 \%$ in 2016). Multivariable logistic regression analysis showed that travel distance, education level, hospital facility type, clinical T stage, tumor size, and year of diagnosis were associated with increased use of NT, whereas comorbidities, uninsured/Medicaid status, South/West geography, left-sided tumor location, and increasing age were associated with immediate surgery (all $P<.001$ ). Based on logistic regressionderived interaction factors, the association between NT use and median income, education level, Midwest location, clinical T stage, and clinical $N$ stage significantly increased over time (all $P<.01$ ). Conclusions: In addition to traditional clinicopathologic factors, several demographic, socioeconomic, and hospital-related factors are associated with use of NT for PDAC. Because NT is used increasingly for PDAC, efforts to reduce disparities will be critical in improving outcomes for all patients with pancreatic cancer.
\end{abstract}

J Natl Compr Canc Netw 2020;18(5):556-563 doi: 10.6004/jnccn.2019.7380

${ }^{1}$ Division of Surgical Oncology, Department of Surgery, and the Center for Surgical Health Assessment, Research, and Policy, The Ohio State University Wexner Medical Center, Columbus, Ohio.

\section{Background}

Pancreatic ductal adenocarcinoma (PDAC) is the third most common cause of cancer-related death in the United States and long-term outcomes remain dismal, with a 5 -year overall survival rate of $9 \% .^{1}$ The incidence of PDAC is increasing, and it is expected to become the second most common cause of cancer-related mortality over the next few decades. Although surgical resection of localized pancreatic cancers is necessary for curativeintent treatment, most patients will develop recurrent disease. Although adjuvant chemotherapy improves survival for all patients with resected PDAC, ${ }^{2,3}$ up to $50 \%$ of patients will not initiate postoperative chemotherapy, typically because of poor performance status after major surgery. ${ }^{4-6}$ A greater number of patients will be unable to complete the intended course of adjuvant therapy for similar reasons. ${ }^{7,8}$

The administration of chemotherapy with or without radiation therapy (RT) before surgical resection is an alternative strategy that ensures its early and near universal delivery. Neoadjuvant therapy (NT) offers several other theoretical benefits including improved margin-negative resection rates, decreased lymph node positivity, early treatment of presumed micrometastatic disease, and the ability to measure in vivo response to therapy histologically after resection. ${ }^{9-14}$ In addition, evidence of improved survival with this approach has been supported by results from large cancer databases, ${ }^{12}$ meta-analyses of nonrandomized trials, ${ }^{15-17}$ Markov decision analysis models, ${ }^{18,19}$ and randomized controlled trials. ${ }^{20,21}$

Based on this evidence, recent practice guidelines have recognized use of NT as the preferred treatment strategy for patients with borderline resectable cancer and as an acceptable treatment option for patients with potentially resectable cancer. ${ }^{22,23}$ Nevertheless, although NT has become the preferred treatment strategy at some high-volume referral centers in the United States, its

See JNCCN.org for supplemental online content. 
overall use for patients with PDAC is low. Indeed, which patients are selected for NT and whether disparities exist in the use of NT for PDAC are not well understood. Therefore, the objective of this study was to examine trends in the indications for NT among patients with resectable PDAC using a population-based approach.

\section{Methods}

We performed a retrospective review of adult patients from the National Cancer Database (NCDB) from 2004 through 2016. The NCDB is a national cancer registry that includes data from more than 1,500 Commission on Cancer-accredited facilities. Jointly sponsored by the American College of Surgeons and American Cancer Society, it currently captures more than $70 \%$ of newly diagnosed cancers within the United States. Relevant patient characteristics, tumor staging, type of initial treatment provided, and long-term survival outcomes are recorded by trained registrars according to nationally standardized coding definitions. ${ }^{24,25}$ For the purposes of this study, the most currently available participant use file containing data from 2004 through 2016 was used. All patients with stage I-II PDAC who underwent pancreatectomy were included. Patients with clinical T4 lesions and those with unknown treatment sequencing status were excluded. NT was defined as receipt of chemotherapy or RT before curative-intent surgical resection.

Demographic, socioeconomic, treatment facility, clinical, and treatment-related variables were abstracted from the NCDB. The Charlson-Deyo score was used to categorize comorbidities. Travel distance, median income, and percentage of individuals without a high school degree were recorded based on the county of residence and reported as quartiles. Region was defined as metropolitan, urban, or rural, whereas geography was defined as East, West, South, or Midwest. Tumor, including clinical and pathologic TNM stages as defined by the AJCC, and treatment-related factors were also abstracted.

Demographic, socioeconomic, clinical, and histopathologic factors of patients who underwent immediate surgery were compared with those of patients who received NT before surgery. Continuous variables were compared using $t$ test, whereas categorical variables were compared using the chi-square test. Univariable logistic regressions were performed to assess for factors independently associated with NT. Multivariable logistic regression was performed using clinically relevant factors and those significantly related to NT on the univariate regressions. Finally, changes in the impact of predictive clinicopathologic factors and receipt of NT over time were measured. Candidate variables were assessed by measuring interaction factors with time using logistic regression. The changing relationship with NT use over time among the variables with statistically significant interaction factors was then further investigated by measuring the odds ratio $(\mathrm{OR})$ and confidence interval at each time point during the study period. Statistical significance was set at 2-sided $\alpha<0.05$. All statistical analyses were performed using STATA, version 15.1 (StataCorp LLC)

\section{Results}

Among 58,124 patients who underwent pancreatectomy in the NCDB from 2004 through 2016, 8,124 (14.0\%) received NT and 50,000 (86.0\%) did not. NT consisted of chemotherapy alone (51.3\%), chemotherapy and RT (46.7\%), or RT alone (2.1\%). Use of NT increased significantly throughout the study period (from $3.5 \%$ in 2004 to $26.4 \%$ in 2016), primarily related to increases in the percentage of patients who received chemotherapy alone (from $0.6 \%$ in 2004 to $17.9 \%$ in 2016) (Figure 1).

Characteristics of patients undergoing immediate surgery versus NT followed by surgery are reported in Table 1. Statistically significant differences were observed in most variables, partly due to the large sample size. In general, patients who received NT were younger (mean age, $64.08 \pm 9.70$ vs $66.68 \pm 10.55$ years), had greater travel distance ( $>38.8$ miles: $34.0 \%$ vs $26.8 \%$ ), were more likely to have private insurance ( $44.4 \%$ vs $35.6 \%$ ), and had received care at an academic/research facility $(65.6 \%$ vs $54.1 \%$ ). They were also more likely to have more advanced clinical stage disease (cT3: $55.8 \%$ vs $27.6 \%$; cN1: $27.5 \%$ vs $17.4 \%$ ) and larger tumors (mean $2.6 \pm 4.1$ vs $1.5 \pm 3.1 \mathrm{~cm}$ ) but less likely to have left-sided tumors requiring distal pancreatectomy $(9.7 \%$ vs $15.1 \%)$.

Table 2 reports the results of multivariable logistic regression of factors independently associated with NT use. Increasing travel distance, higher education level, hospital facility type (ie, academic/research facility or an integrated network cancer program compared with a community cancer program), higher clinical T stage, larger tumor size, and more recent year of diagnosis were

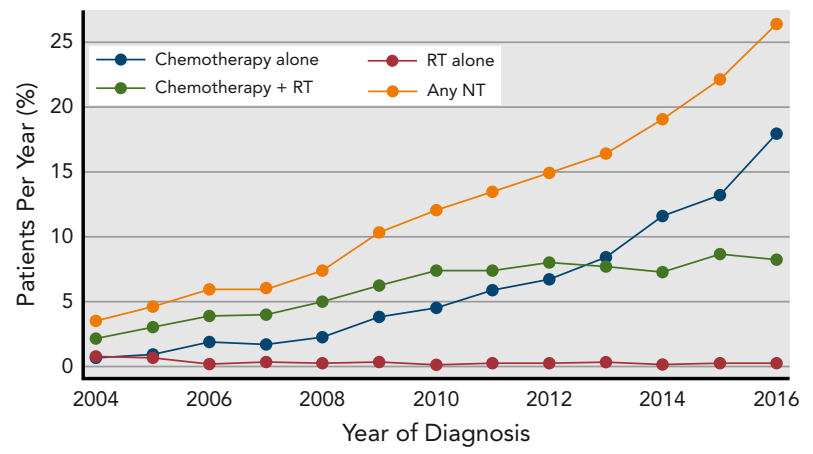

Figure 1. Trends in the percentage of patients with stage I-II resected pancreatic cancer who received NT before surgery.

Abbreviations: NT, neoadjuvant therapy; RT, radiation therapy. 
Table 1. Characteristics of Patients Undergoing Immediate Surgery Versus NT and Surgery

\begin{tabular}{|c|c|c|c|}
\hline & $\begin{array}{c}\text { Immediate Surgery } \\
\text { n (\%) }\end{array}$ & $\begin{array}{c}\text { NT } \\
\text { n (\%) }\end{array}$ & $P$ Value \\
\hline Total, $\mathrm{n}$ & 50,000 & 8,124 & \\
\hline Age, mean (SD), y & $66.68(10.55)$ & $64.08(9.70)$ & $<.001$ \\
\hline Sex & & & .31 \\
\hline Male & 25,447 (50.9\%) & 4,184 (51.5\%) & \\
\hline Female & $24,553(49.1 \%)$ & 3,940 (48.5\%) & \\
\hline Race & & & $<.001$ \\
\hline White & $42,881(85.8 \%)$ & 7,087 (87.2\%) & \\
\hline Black & 4,845 (9.7\%) & 738 (9.1\%) & \\
\hline Other ${ }^{a}$ & $2,274(4.5 \%)$ & 299 (3.7\%) & \\
\hline Charlson-Deyo score & & & $<.001$ \\
\hline 0 & 32,457 (64.9\%) & $5,454(67.1 \%)$ & \\
\hline 1 & $13,147(26.3 \%)$ & 2,051 (25.2\%) & \\
\hline 2 & 3,142 (6.3\%) & 444 (5.5\%) & \\
\hline$\geq 3$ & $1,254(2.5 \%)$ & $175(2.2 \%)$ & \\
\hline Travel distance, miles & & & $\leq .001$ \\
\hline$\leq 5.5$ & $11,212(22.5 \%)$ & 1,321 (16.3\%) & \\
\hline$>5.5-13.6$ & $12,136(24.3 \%)$ & $1,782(22.0 \%)$ & \\
\hline$>13.6-38.8$ & $13,153(26.4 \%)$ & 2,242 (27.7\%) & \\
\hline$>38.8$ & $13,339(26.8 \%)$ & 2,755 (34.0\%) & \\
\hline Insurance status & & & $<.001$ \\
\hline Not insured & $1,200(2.4 \%)$ & $124(1.5 \%)$ & \\
\hline Private & 17,787 (35.6\%) & 3,603 (44.4\%) & \\
\hline Medicaid & $2,240(4.5 \%)$ & $346(4.3 \%)$ & \\
\hline Medicare & $27,428(54.9 \%)$ & $3,727(45.9 \%)$ & \\
\hline Other government & $570(1.1 \%)$ & $114(1.4 \%)$ & \\
\hline Unknown & 775 (1.6\%) & $210(2.6 \%)$ & \\
\hline Median income, \$USD & & & $<.001$ \\
\hline$<\$ 38,000$ & 8,089 (16.2\%) & $1,138(14.1 \%)$ & \\
\hline$\$ 38,000-\$ 47,999$ & 11,219 (22.5\%) & $1,896(23.4 \%)$ & \\
\hline$\$ 48,000-\$ 62,999$ & $13,201(26.5 \%)$ & 2,268 (28.0\%) & \\
\hline$\geq \$ 63,000$ & $17,281(34.7 \%)$ & $2,790(34.5 \%)$ & \\
\hline$\%$ No high school degree & & & $<.001$ \\
\hline$\geq 21.0 \%$ & $7,627(15.3 \%)$ & $980(12.1 \%)$ & \\
\hline $13.0 \%-20.9 \%$ & $12,789(25.7 \%)$ & $1,909(23.6 \%)$ & \\
\hline $7.0 \%-12.9 \%$ & $16,445(33.0 \%)$ & $2,884(35.6 \%)$ & \\
\hline$<7.0 \%$ & $12,950(26.0 \%)$ & $2,323(28.7 \%)$ & \\
\hline Region & & & .002 \\
\hline Metropolitan & $39,908(82.1 \%)$ & $6,359(80.4 \%)$ & \\
\hline Urban & $7,691(15.8 \%)$ & $1,369(17.3 \%)$ & \\
\hline Rural & $1,021(2.1 \%)$ & $179(2.3 \%)$ & \\
\hline Facility type & & & $<.001$ \\
\hline Community cancer program & $15,964(32.2 \%)$ & $1,822(22.6 \%)$ & \\
\hline Academic/Research program & $26,803(54.1 \%)$ & $5,279(65.6 \%)$ & \\
\hline Integrated network cancer program & $6,792(13.7 \%)$ & 949 (11.8\%) & \\
\hline
\end{tabular}




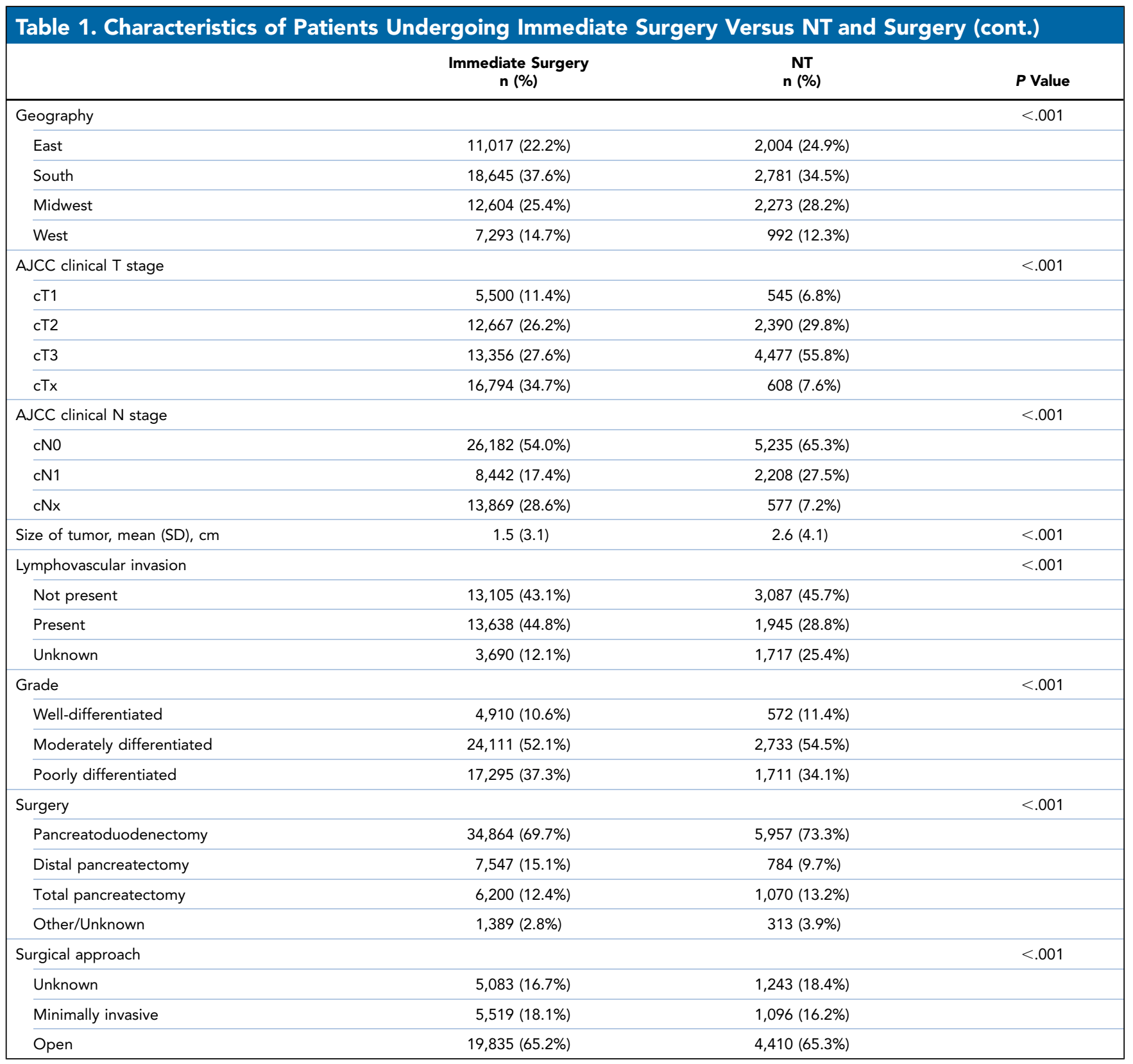

Abbreviation: NT, neoadjuvant therapy.

alncluding nonwhite/black.

all associated with an increased use of NT (all $P<.001$ ). In addition, higher comorbidities, uninsured/Medicaid status, South/West geography (vs East), left-sided tumor location, and increasing age were inversely associated with NT.

Changes in association with NT use over time were assessed via logistic regression interaction factors (supplemental eFigure 1, available with this article at JNCCN.org). The association between NT use and yearly median income ( $\geq \$ 63,000$ : OR, 1.03; 95\% CI, 1.01-1.06; $P<.01$ ), education level $(<7 \%$ without high school degree: OR,
1.04; 95\% CI, 1.02-1.07; $P<.01$ ), Midwest location (OR, 1.04; 95\% CI, 1.02-1.07; $P<.01$ ), clinical T stage (cT3: OR, 1.05; 95\% CI, 1.02-1.09; $P<.01$ ), and clinical $\mathrm{N}$ stage (cN1: OR, 1.06; 95\% CI, 1.04-1.08; $P<.01$ ) significantly increased over time, whereas tumor size (OR, 0.99; 95\% CI, 0.99-0.99; $P<.001$ ) decreased. The changing ORs of these factors over time are displayed in Figure 2.

\section{Discussion}

An increasing body of literature supports the use of NT in the management of localized PDAC given its 
Table 2. Multivariable Logistic Regression for Receipt of Neoadjuvant Therapy Before Surgical Resection

\begin{tabular}{|c|c|c|c|}
\hline & OR & $95 \% \mathrm{Cl}$ & $P$ Value \\
\hline Age & 0.97 & $0.97-0.97$ & $<.001$ \\
\hline \multicolumn{4}{|l|}{ Sex } \\
\hline Male & Ref & & \\
\hline Female & 1.04 & $0.98-1.09$ & .19 \\
\hline \multicolumn{4}{|l|}{ Race } \\
\hline White & Ref & & \\
\hline Black & 0.97 & $0.90-1.08$ & .77 \\
\hline Other ${ }^{a}$ & 0.79 & $0.69-0.91$ & .001 \\
\hline \multicolumn{4}{|l|}{ Charlson-Deyo score } \\
\hline 0 & Ref & & \\
\hline 1 & 0.97 & $0.91-1.03$ & .29 \\
\hline 2 & 0.89 & $0.80-1.00$ & .05 \\
\hline$\geq 3$ & 0.81 & $0.68-0.96$ & .02 \\
\hline \multicolumn{4}{|l|}{ Travel distance, miles } \\
\hline$\leq 5.5$ & Ref & & \\
\hline$>5.5-13.6$ & 1.17 & $1.08-1.27$ & $<.001$ \\
\hline$>13.6-38.8$ & 1.25 & $1.15-1.35$ & $<.001$ \\
\hline$>38.8$ & 1.47 & $1.35-1.61$ & $<.001$ \\
\hline \multicolumn{4}{|l|}{ Insurance status } \\
\hline Private & Ref & & \\
\hline Not insured & 0.55 & $0.44-0.67$ & $<.001$ \\
\hline Medicaid & 0.73 & $0.64-0.84$ & $<.001$ \\
\hline Medicare & 0.94 & $0.88-1.09$ & .08 \\
\hline Other government & 1.06 & $0.85-1.33$ & .61 \\
\hline Unknown & 1.71 & $1.41-2.07$ & $<.001$ \\
\hline \multicolumn{4}{|l|}{ Median income, \$USD } \\
\hline$<\$ 38,000$ & Ref & & \\
\hline$\$ 38,000-\$ 47,999$ & 1.07 & $0.98-1.18$ & .14 \\
\hline$\$ 48,000-\$ 62,999$ & 1.01 & $0.91-1.11$ & .91 \\
\hline$\geq \$ 63,000$ & 0.83 & $0.74-0.93$ & .001 \\
\hline \multicolumn{4}{|l|}{$\%$ No high school degree } \\
\hline$\geq 21.0 \%$ & Ref & & \\
\hline $13.0 \%-20.9 \%$ & 1.14 & $1.04-1.25$ & .01 \\
\hline $7.0 \%-12.9 \%$ & 1.40 & $1.27-1.55$ & $<.001$ \\
\hline$<7.0 \%$ & 1.60 & $1.43-1.79$ & $<.001$ \\
\hline \multicolumn{4}{|l|}{ Region } \\
\hline Metropolitan & Ref & & \\
\hline Urban & 1.00 & $0.92-1.08$ & .99 \\
\hline Rural & 1.04 & $0.87-1.25$ & .68 \\
\hline \multicolumn{4}{|l|}{ Facility type } \\
\hline Community cancer program & Ref & & \\
\hline Academic/Research program & 1.51 & $1.42-1.62$ & $<.001$ \\
\hline Integrated network cancer program & 1.21 & $1.11-1.33$ & $<.001$ \\
\hline
\end{tabular}

(continued)

\begin{tabular}{|c|c|c|c|}
\hline & OR & $95 \% \mathrm{Cl}$ & $P$ Value \\
\hline \multicolumn{4}{|l|}{ Geography } \\
\hline East & Ref & & \\
\hline South & 0.79 & $0.74-0.85$ & $<.001$ \\
\hline Midwest & 0.94 & $0.87-1.01$ & .08 \\
\hline West & 0.77 & $0.70-0.84$ & $<.001$ \\
\hline \multicolumn{4}{|l|}{ AJCC clinical T stage } \\
\hline cT1 & Ref & & \\
\hline cT2 & 2.01 & $1.82-2.23$ & $<.001$ \\
\hline cT3 & 3.69 & $3.34-4.09$ & $<.001$ \\
\hline cTx & 0.55 & $0.47-0.63$ & $<.001$ \\
\hline \multicolumn{4}{|l|}{ AJCC clinical N stage } \\
\hline cNO & Ref & & \\
\hline cN1 & 0.99 & $0.93-1.05$ & .65 \\
\hline $\mathrm{cNx}$ & 0.98 & $0.86-1.10$ & .69 \\
\hline Size of tumor & 1.00 & $1.00-1.00$ & $<.001$ \\
\hline \multicolumn{4}{|l|}{ Surgery } \\
\hline Pancreatoduodenectomy & Ref & & \\
\hline Distal pancreatectomy & 0.59 & $0.54-0.64$ & $<.001$ \\
\hline Total pancreatectomy & 1.07 & $0.99-1.15$ & .11 \\
\hline Other/Unknown & 1.31 & $0.13-1.52$ & $<.001$ \\
\hline Year of diagnosis & 1.16 & $1.15-1.17$ & $<.001$ \\
\hline
\end{tabular}

Abbreviation: $\mathrm{OR}$, odds ratio.

alncluding nonwhite/black.

association with improved margin- and lymph nodenegative resection rates, the opportunity to ensure nearuniversal receipt of nonsurgical therapies, and the early prioritization of systemic therapy for a primarily systemic disease. Nevertheless, little research has explored the characteristics of patients who receive NT from a population-based perspective. Results of our study highlight several important findings. First, the proportion of patients receiving NT before surgical resection is increasing rapidly, and is primarily driven by those who receive systemic chemotherapy alone. Second, in addition to traditional clinicopathologic factors, several demographic, socioeconomic, and hospital-related factors are associated with use of NT for PDAC, suggesting the possibility of health-related disparities in receipt of this treatment approach. Third, the strength of the association between NT and time has been increasing among those with higher median incomes and education levels and those with more advanced $\mathrm{T}$ and $\mathrm{N}$ stage tumors.

Previous population-based analyses investigating trends in the use of NT for PDAC have shown increases, 
A

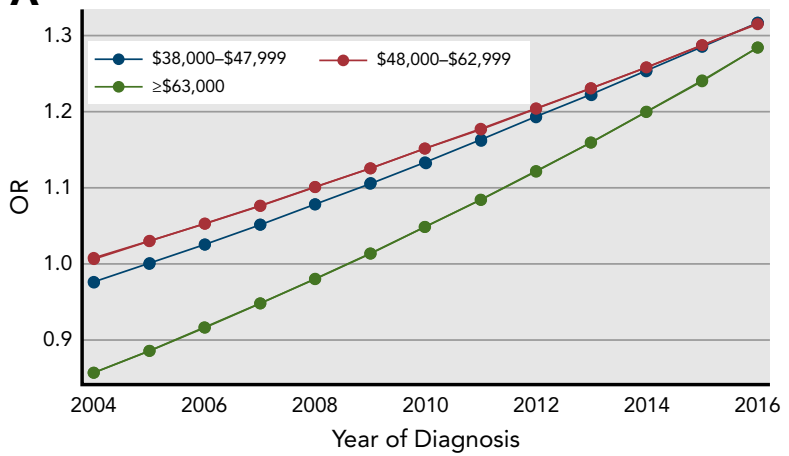

C

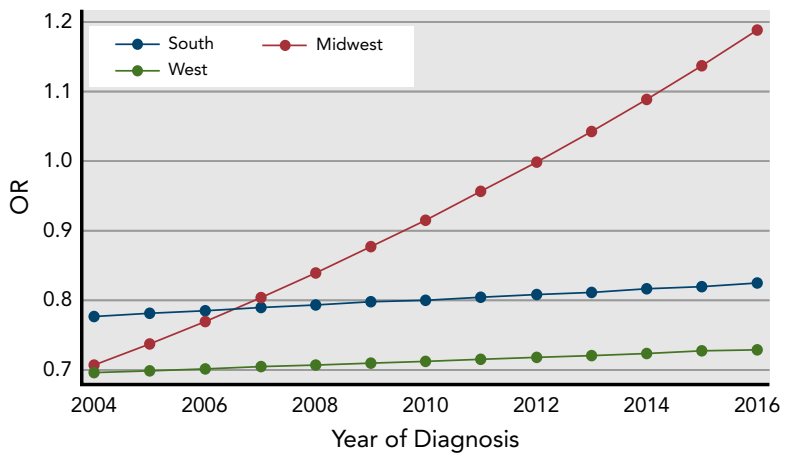

E

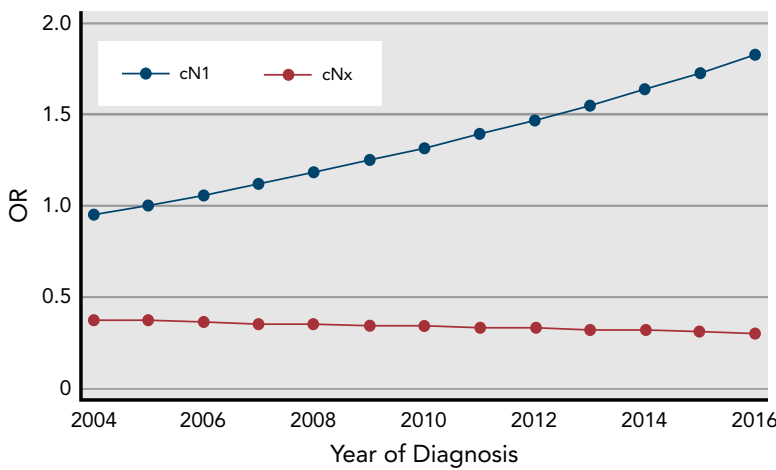

B

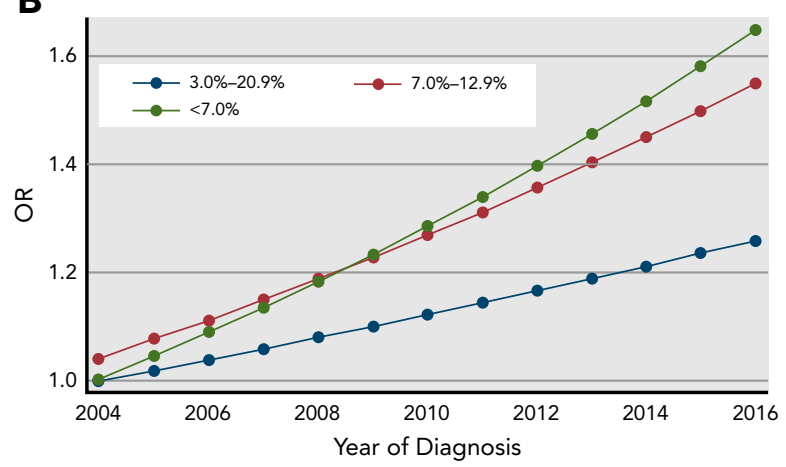

D

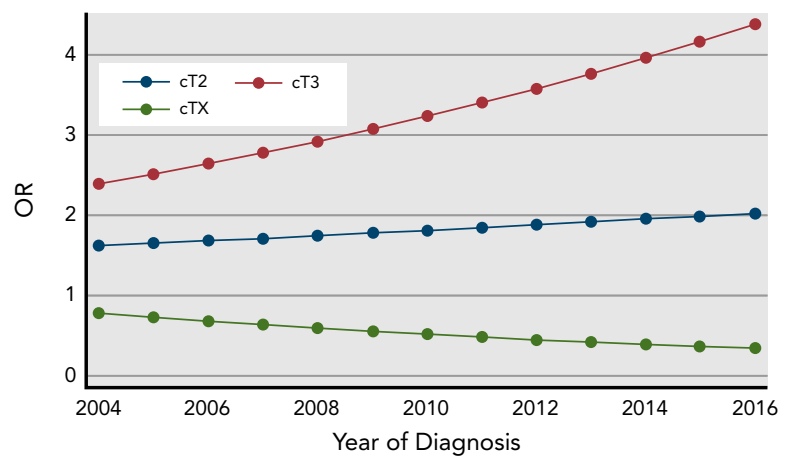

$\mathbf{F}$

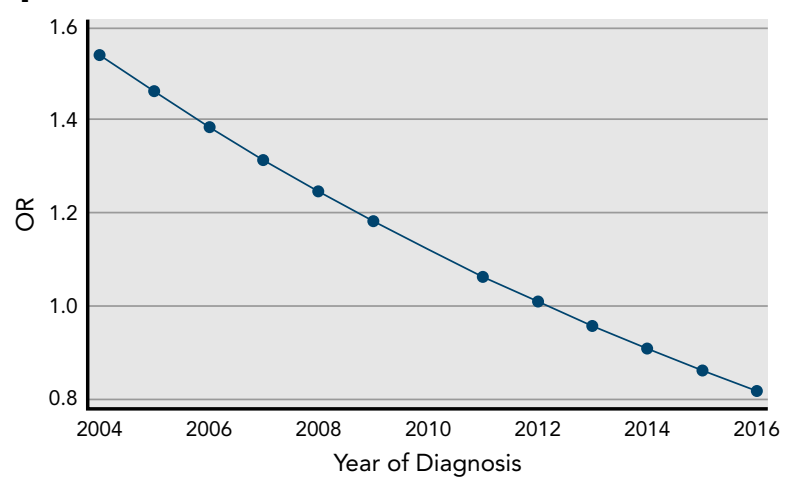

Figure 2. Trends in the calculated ORs of each factors' association with neoadjuvant therapy over time: $(\mathrm{A})$ median income (baseline, $<\$ 38,000)$, (B) education level (baseline, $\geq 21.0 \%$ with no high school degree), (C) geographic location (baseline, East), (D) clinical $T$ stage (baseline, cT1), (E) clinical N stage (baseline, cNO), and (F) tumor size (for a 10-cm tumor).

Abbreviation: OR, odds ratio.

but its overall use in the United States has remained low $(<20 \%) .^{10,26}$ Our study using the most contemporary data from the NCDB shows that these trends have continued, with approximately $26 \%$ of patients with resected PDAC having received NT in 2016. Despite these trends, these low rates remain in stark contrast to the routine use of NT in other cancers to improve overall survival, ${ }^{27}$ margin-negative resection rates, ${ }^{28}$ and local recurrence, ${ }^{29}$ or to facilitate less invasive surgery. ${ }^{30}$ Although an ongoing evolution of practice changes will be expected as evidence supporting the efficacy of NT accumulates, further investigation into the reasons for the relatively low use rates of NT observed in PDAC would be indicated.

Few studies have previously investigated which patients are selected to receive NT. Some studies have found that younger patient age is associated with receipt of NT. ${ }^{10,26}$ Our study confirms this association but also notes that patients with a greater number of 
comorbidities, without private insurance, who live in counties with lower median incomes and education levels, or are treated at community cancer programs were less likely to receive NT. These findings are similar to those of recent studies highlighting the existence of disparities in receipt of chemotherapy after pancreatectomy based on age, race, insurance coverage, and socioeconomic status., ${ }^{4,31-33}$ The finding that increased travel distance was independently associated with greater use of NT was unexpected, and may reflect that patients who are able and willing to travel long distances to high-volume referral centers are subsequently more likely to be treated with NT. ${ }^{34,35}$ By evaluating the interaction between NT use, time, and covariates, our findings indicate that some disparities in NT use, namely based on socioeconomic status and geographic location, may be worsening over time.

Identifying which factors are associated with the receipt of NT is important for identifying disparities in the multidisciplinary care of patients with PDAC. Highlighting these disparities could lead to interventions that increase NT use rates. For example, early evidence suggests improved oncologic outcomes among hospitals that are high users of $\mathrm{NT}^{36}$; therefore, providing feedback to low-use hospitals could represent an opportunity for quality improvement. Ensuring adequate access for all patients to facilities that provide NT is equally important. Finally, initiatives that educate patients and providers about the potential advantages and disadvantages of NT for PDAC should be emphasized.

Little is known about how treatment decisionmaking occurs for patients with resectable PDAC and whether specific barriers to the use of NT exist. Further data on patient and physician preferences and the patient experience during NT may highlight opportunities to improve shared decision-making and allocate necessary resources before and during treatment. One potential barrier to the use of NT is concerns regarding treatment toxicities that may preclude the eventual receipt of surgery. Although previous studies have reported the dropout rate during NT due to worsening performance status to be extremely low, ${ }^{37,38}$ these concerns may be amplified at lower-volume hospitals that may not have the necessary resources to manage toxicities associated with NT, instead opting to select patients for immediate surgery. As use of more-intense chemotherapy regimens (eg, mFOLFIRINOX) in NT increases, these disparities could worsen. Additional research is needed into potential barriers and facilitators to ensure that all patients have access to multimodality therapy for PDAC.
Although our study represents one of the first efforts to specifically evaluate the characteristics of patients receiving NT for PDAC using a populationbased approach, the findings should be interpreted within the context of its limitations. First, given the retrospective nature of the study and the inclusion of only patients with resected PDACs, we were unable to identify and include patients who received NT with a curative intent but ultimately did not undergo surgery. Although prior studies have suggested this occurs relatively infrequently among patients with resectable cancers, ${ }^{37}$ this omission may bias the results in unpredictable ways. Second, we included patients with stage I and II cancers as a surrogate for resectable disease because the NCDB does not currently include data on anatomic staging classification systems. Similarly, we chose to exclude patients with stage III cancers to minimize the selection bias of patients with borderline resectable or locally advanced cancers that were treated with NT and successfully resected. Third, although the NCDB contains comprehensive demographic, socioeconomic, clinical, and treatment-related information, some data that could potentially influence the decision to administer NT (eg, CA 19-9 levels) and specific information on NT used (eg, chemotherapy regimen, RT modality) are not available.

\section{Conclusions}

In this contemporary population-based cancer registry, the use of NT for localized PDAC is increasing, primarily due to increases in the use of chemotherapy alone without RT before pancreatectomy. In addition to traditional clinicopathologic factors, several demographic, socioeconomic, and hospital-related factors are associated with the use of NT for PDAC, and the strength of some of these associations is increasing over time. Because NT is used increasingly for PDAC, efforts to reduce disparities will be critical to improving the outcomes of all patients with pancreatic cancer.

Submitted September 13, 2019; accepted for publication November 25, 2019.

Author contributions: Study concept: Cloyd, Santry, Bridges, Dillhoff, Ejaz, Pawlik, Tsung. Methodology: Cloyd, Shen, Tsung. Investigation: Cloyd. Visualization: Cloyd. Supervision: Cloyd, Tsung. Formal analysis: Shen. Validation: Tsung. Resources: Tsung. Writing-original draft: Cloyd. Writing-review and editing: All authors. Project administration: Tsung.

Disclosures: The authors have disclosed that they have not received any financial consideration from any person or organization to support the preparation, analysis, results, or discussion of this article.

Correspondence: Jordan M. Cloyd, MD, Division of Surgical Oncology, Department of Surgery, The Ohio State University Wexner Medical Center, 410 West 10th Avenue, N-907 Doan Hall, Columbus, OH 43210. Email: jordan.cloyd@osumc.edu 


\section{References}

1. Siegel RL, Miller KD, Jemal A. Cancer statistics, 2019. CA Cancer J Clin 2019;69:7-34

2. Neoptolemos JP, Stocken DD, Friess H, et al. A randomized trial of chemoradiotherapy and chemotherapy after resection of pancreatic cancer. N Engl J Med 2004;350:1200-1210.

3. Oettle H, Post S, Neuhaus P, et al. Adjuvant chemotherapy with gemcitabine vs observation in patients undergoing curative-intent resection of pancreatic cancer: a randomized controlled trial. JAMA 2007;297:267-277.

4. Bilimoria KY, Bentrem DJ, Ko CY, et al. Multimodality therapy for pancreatic cancer in the U.S.: utilization, outcomes, and the effect of hospital volume. Cancer 2007;110:1227-1234.

5. Mayo SC, Gilson MM, Herman JM, et al. Management of patients with pancreatic adenocarcinoma: national trends in patient selection, operative management, and use of adjuvant therapy. J Am Coll Surg 2012;214:33-45.

6. Simons JP, Ng SC, McDade TP, et al. Progress for resectable pancreatic [corrected] cancer?: a population-based assessment of US practices [published correction appears in Cancer 2010;116:2503]. Cancer 2010; 116:1681-1690.

7. Valle JW, Palmer D, Jackson R, et al. Optimal duration and timing of adjuvant chemotherapy after definitive surgery for ductal adenocarcinoma of the pancreas: ongoing lessons from the ESPAC-3 study. J Clin Oncol 2014;32:504-512.

8. Altman AM, Wirth $\mathrm{K}$, Marmor $\mathrm{S}$, et al. Completion of adjuvant chemotherapy after upfront surgical resection for pancreatic cancer is uncommon yet associated with improved survival. Ann Surg Oncol 2019;26: 4108-4116.

9. Cloyd JM, Katz MHG, Prakash L, et al. Preoperative therapy and pancreatoduodenectomy for pancreatic ductal adenocarcinoma: a 25-year single-institution experience. J Gastrointest Surg 2017;21:164-174.

10. Youngwirth LM, Nussbaum DP, Thomas S, et al. Nationwide trends and outcomes associated with neoadjuvant therapy in pancreatic cancer: an analysis of 18,243 patients. J Surg Oncol 2017;116:127-132.

11. Cloyd JM, Wang H, Egger ME, et al. Association of clinical factors with a major pathologic response following preoperative therapy for pancreatic ductal adenocarcinoma. JAMA Surg 2017;152:1048-1056.

12. Mokdad AA, Minter RM, Zhu H, et al. Neoadjuvant therapy followed by resection versus upfront resection for resectable pancreatic cancer: a propensity score matched analysis. J Clin Oncol 2017;35:515-522.

13. Estrella JS, Rashid A, Fleming JB, et al. Post-therapy pathologic stage and survival in patients with pancreatic ductal adenocarcinoma treated with neoadjuvant chemoradiation. Cancer 2012;118:268-277.

14. Sugimoto M, Takahashi N, Farnell MB, et al. Survival benefit of neoadjuvant therapy in patients with non-metastatic pancreatic ductal adenocarcinoma: a propensity matching and intention-to-treat analysis. J Surg Oncol 2019;120:976-984.

15. Versteijne E, Vogel JA, Besselink MG, et al. Meta-analysis comparing upfront surgery with neoadjuvant treatment in patients with resectable or borderline resectable pancreatic cancer. Br J Surg 2018;105:946-958.

16. Bradley A, Van Der Meer R. Upfront surgery versus neoadjuvant therapy for resectable pancreatic cancer: systematic review and bayesian network meta-analysis. Sci Rep 2019;9:4354.

17. Unno M, Hata T, Motoi F. Long-term outcome following neoadjuvant therapy for resectable and borderline resectable pancreatic cancer compared to upfront surgery: a meta-analysis of comparative studies by intention-to-treat analysis. Surg Today 2019;49:295-299.

18. de Geus SWL, Evans DB, Bliss LA, et al. Neoadjuvant therapy versus upfront surgical strategies in resectable pancreatic cancer: a Markov decision analysis. Eur J Surg Oncol 2016;42:1552-1560.

19. Ren $X$, Wei $X$, Ding $Y$, et al. Comparison of neoadjuvant therapy and upfront surgery in resectable pancreatic cancer: a meta-analysis and systematic review. OncoTargets Ther 2019;12:733-744.
20. Van Tienhoven G, Versteijne $E$, Suker $M$, et al. Preoperative chemoradiotherapy versus immediate surgery for resectable and borderline resectable pancreatic cancer (PREOPANC-1): a randomized, controlled, multicenter phase III trial [abstract]. J Clin Oncol 2018;36(Suppl):Abstract LBA4002.

21. Jang JY, Han $Y$, Lee $H$, et al. Oncological benefits of neoadjuvant chemoradiation with gemcitabine versus upfront surgery in patients with borderline resectable pancreatic cancer: a prospective, randomized, open-label, multicenter phase 2/3 trial. Ann Surg 2018;268:215-222.

22. Khorana AA, Mangu PB, Berlin J, et al. Potentially curable pancreatic cancer: American Society of Clinical Oncology clinical practice guideline. J Clin Oncol 2016;34:2541-2556.

23. Tempero MA, Malafa MP, Al-Hawary M, et al. NCCN Clinical Practice Guidelines in Oncology: Pancreatic Adenocarcinoma. Version 3.2019. Accessed November 13, 2019. To view the most recent version, visit NCCN.org.

24. Raval MV, Bilimoria KY, Stewart AK, et al. Using the NCDB for cancer care improvement: an introduction to available quality assessment tools. J Surg Oncol 2009;99:488-490.

25. Boffa DJ, Rosen JE, Mallin K, et al. Using the National Cancer Database for outcomes research: a review. JAMA Oncol 2017;3:1722-1728.

26. Hashmi A, Kozick Z, Fluck M, et al. Neoadjuvant versus adjuvant che motherapy for resectable pancreatic adenocarcinoma: a National Cance Database analysis. Am Surg 2018;84:1439-1445.

27. Cunningham D, Allum WH, Stenning SP, et al. Perioperative chemotherapy versus surgery alone for resectable gastroesophageal cancer. N Engl J Med 2006;355:11-20.

28. van Hagen P, Hulshof MCCM, van Lanschot JJB, et al. Preoperative chemoradiotherapy for esophageal or junctional cancer. N Engl J Med 2012;366:2074-2084.

29. Kapiteijn E, Marijnen CAM, Nagtegaal ID, et al. Preoperative radiotherapy combined with total mesorectal excision for resectable rectal cancer. N Engl J Med 2001;345:638-646

30. van der Hage JA, van de Velde CJ, Julien JP, et al. Preoperative chemotherapy in primary operable breast cancer: results from the European Organization for Research and Treatment of Cancer trial 10902. J Clin Oncol 2001;19:4224-4237.

31. Abraham A, Al-Refaie WB, Parsons HM, et al. Disparities in pancreas cancer care. Ann Surg Oncol 2013;20:2078-2087.

32. Boevers $E$, McDowell BD, Mott SL, et al. Insurance status is related to receipt of therapy and survival in patients with early-stage pancreatic exocrine carcinoma. J Cancer Epidemiol 2017;2017:4354592.

33. Davila JA, Chiao EY, Hasche JC et al. Utilization and determinants of adjuvant therapy among older patients who receive curative surgery for pancreatic cancer. Pancreas 2009;38:e18-25.

34. Jindal M, Zheng C, Quadri HS, et al. Why do long-distance travelers have improved pancreatectomy outcomes? J Am Coll Surg 2017;225: 216-225.

35. Makar M, Worple E, Dove J, et al. Disparities in care: impact of socioeconomic factors on pancreatic surgery: exploring the National Cancer Database. Am Surg 2019;85:327-334.

36. Fisher $\mathrm{AV}, \mathrm{Abbott} \mathrm{DE}$, Venkatesh $\mathrm{M}$, et al. The impact of hospital neoadjuvant therapy utilization on survival outcomes for pancreatic cancer. Ann Surg Oncol 2018;25:2661-2668.

37. Christians KK, Heimler JW, George B, et al. Survival of patients with resectable pancreatic cancer who received neoadjuvant therapy. Surgery 2016;159:893-900.

38. Tzeng C-WD, Fleming JB, Lee JE, et al. Defined clinical classifications are associated with outcome of patients with anatomically resectable pancreatic adenocarcinoma treated with neoadjuvant therapy. Ann Surg Oncol 2012;19:2045-2053. 
Supplemental online content for:

\section{Disparities in the Use of Neoadjuvant Therapy for Resectable Pancreatic Ductal Adenocarcinoma}

Jordan M. Cloyd, MD; Chengli Shen, MS; Heena Santry, MD, MS; John Bridges, PhD; Mary Dillhoff, MD, MS; Aslam Ejaz, MD, MPH; Timothy M. Pawlik, MD, MPH, PhD; and Allan Tsung, MD

J Natl Compr Canc Netw 2020;18(5):556-563

eFigure 1: Forest Plot of Interaction Factors Demonstrating Weight of Association With Neoadjuvant Therapy Use Over Time 


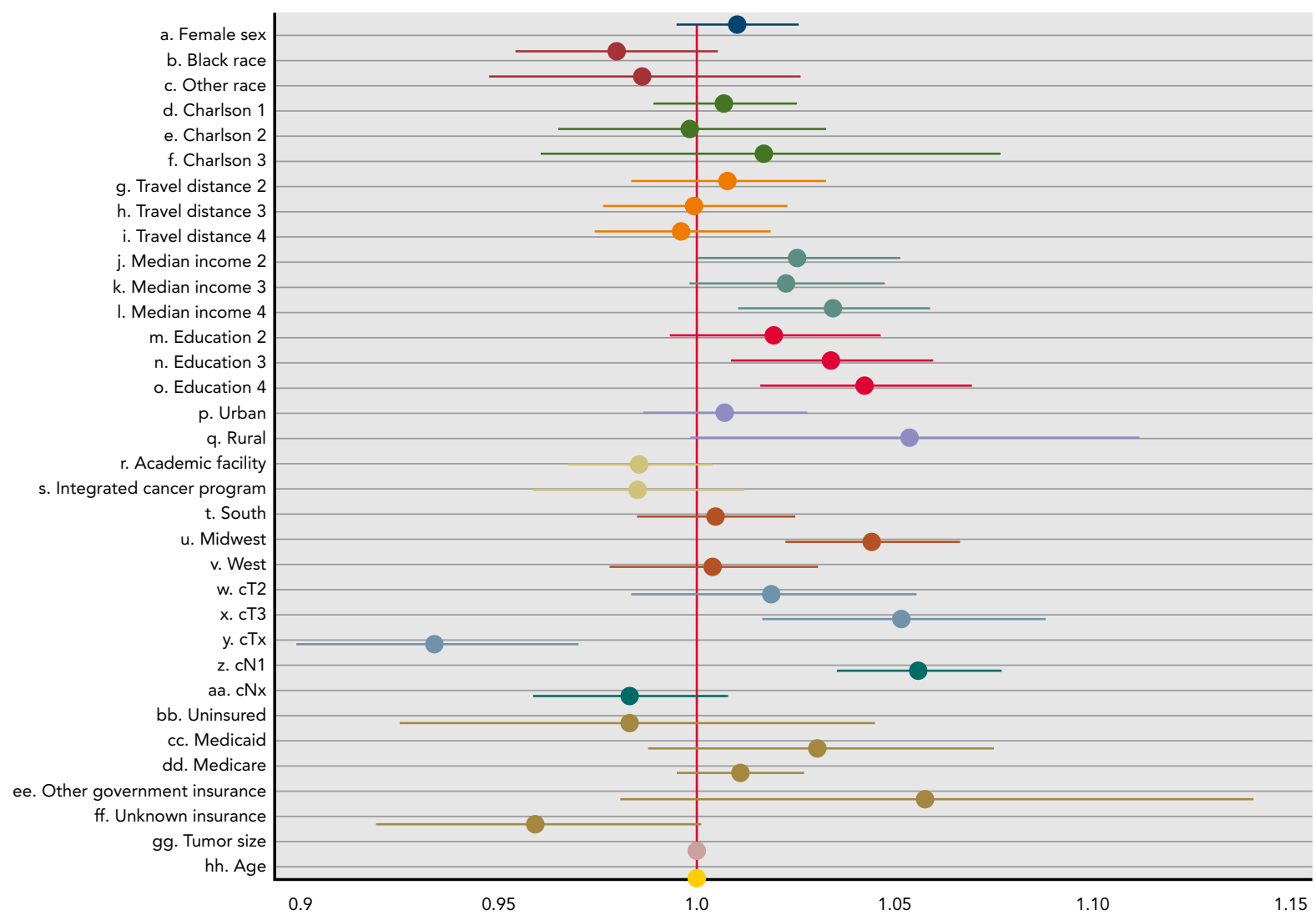

eFigure 1. Forest plot of interaction factors demonstrating weight of association with neoadjuvant therapy use over time. 